\title{
The influence on the blastoderm fate map of maternal-effect genes that affect the antero-posterior pattern in Drosophila
}

\author{
Marek Mlodzik, Catherine M. De Montrion, ${ }^{1}$ Yasushi Hiromi, ${ }^{2}$ Henry $M$. Krause, and Walter J. \\ Gehring \\ Biozentrum, University of Basel, CH-4056 Basel, Switzerland
}

\begin{abstract}
The polarity and the spatial coordinates of the egg and the developing embryo are largely specified by maternal-effect genes. Mutations in several of these genes cause deletions of head structures and, in some cases, their replacement by posterior structures. Here, we analyze embryos derived from females with mutations in the loci exuperantia (exu), torso (tor), trunk (trk), and bicoid (bcd). The effects of these mutations can be monitored at the blastoderm stage, when the outlines of the body plan are laid down, by the visualization of RNA or protein products of genes that are expressed in a spatially restricted pattern. We have used antisera and/or cloned DNA probes to detect the localization of the gene products of the segmentation genes fushi tarazu (ftz) and hairy (h). In exu- embryos, Deformed (Dfd) and caudal (cad) probes were also used as markers of the anterior and posterior ends, respectively. We find that exu, a mutation leading to head defects, has a pronounced long-range effect on the fate map, enlarging the region of the thoracic anlagen in the anterior direction and compressing the abdominal anlagen. In contrast, tor and trk do not change the fate map over the entire embryo but have more localized effects. In embryos derived from $b c d$ mothers, head and thoracic structures are missing and replaced by a duplicated telson, the most posterior structure. These changes can be detected in the blastoderm as an anterior shift of the posterior anlagen and the formation of a posterior ftz stripe at the anterior end.
\end{abstract}

[Key Words: Maternal-effect genes; in situ hybridization; protein localization; fate map; segmentation genes; exuperantia]

Received March 2, 1987; revised version accepted June 10, 1987.

The most prominent feature of insect organization is the subdivision of the body into a series of distinct segments. This process is dependent upon different classes of genes. The first class, the maternal-effect genes, define the general polarity and coordinates of the egg (Nüsslein-Volhard 1979). After fertilization, this positional information provided by (the products of) these genes becomes interpreted and refined by differential expression of the zygotically active segmentation genes (Nüsslein-Volhard and Wieschaus 1980), and at the cellular blastoderm stage, defined groups of cells become committed to specific pathways of determination by the selective activation of homeotic genes /Chan and Gehring 1971; Garcia-Bellido 1975; Wieschaus and Gehring 1976; Lawrence and Morata 1977).

Mutations in the maternal-effect genes generally result in a severe disruption of pattern formation by changing coordinates along the antero-posterior and the dorso-ventral axes (Bull 1966; Nüsslein-Volhard 1977;

1Present address: 15, rue Jean Faurés,

F-92260 Fontenay aux-Roses, France.

${ }^{2}$ Present address: Department of Biological Sciences, Stanford University, Stanford, California 94305 USA.
Lohs-Schardin 1982; Anderson and Nüsslein-Volhard 1984; Frohnhöfer and Nüsslein-Volhard 1986; MacDonald and Struhl 1986; Mohler and Wieschaus 1986). In general, mutations of this class lead to a deletion of structures from one region of the embryo and their replacement by structures from other coordinates. The most severe mutations of this type disrupting the antero-posterior axis are bicaudal (bic) (Bull 1966; Nüsslein-Volhard 1977; Mohler and Wieschaus 1986) and dicephalic (dic) (Lohs-Schardin 1982), which cause a more or less exact mirror image duplication of posterior (bic) or anterior (dic) pattern(s), albeit with variable expressivity. More recently, maternal-effect genes have been identified which, when mutated, result in the deletion of specific regions or parts of the body plan (Schüpbach and Wieschaus 1986a,b; Lehmann and Nüsslein-Volhard 1986). For example, mutants of the "grandchildlessknirps" group (Boswell and Mahowald 1985; Lehmann and Nüsslein-Volhard 1986; Schüpbach and Wieschaus $1986 \mathrm{a}, \mathrm{b})$ show deletions of the abdomen, whereas the head, thorax, and the telson, the posterior-most segment of the embryo, develop normally.

Mutations in the maternal locus exuperantia (exu) 
(Schüpbach and Wieschaus 1986a,b) show defects in head formation and duplication of posterior structures at the anterior end. However, this duplication does not comprise any ectodermal structures that are visible in the larval cuticle, as is the case for bic and bicoid $(b c d)$ mutations (Bull 1966; Nüsslein-Volhard 1977; Frohnhöfer and Nüsslein-Volhard 1986; Mohler and Wieschaus 1986). Only endodermal tissues, such as the posterior midgut and (in some of the embryos), the Malpighian tubules, are duplicated.

Another class of maternal loci leads to deletions at both poles, that is, the anterior as well as the posterior end, and no duplications are present. Two loci, namely torso (tor) and trunk (trk) (Schüpbach and Wieschaus $1986 \mathrm{a}, \mathrm{b}$ ), belong to this class. The anterior defects of this class lead to similar, although not identical, deletions of head structures (Schüpbach and Wieschaus 1986a,b) that closely resemble those found in $e x u$, but there is no replacement by posterior structures. A number of different explanations for how these pattern deletions occur are possible. One of them would assume strictly localized gene products or determinants that specify the structures that are missing in the mutant embryo. Alternatively, there may be long-range effects of these gene products affecting large regions of the fate map, and the entire fate map or parts of it might be shifted either in the anterior or posterior direction. These genes are presumably active prior to the cellular blastoderm when the nuclei still form a syncytium and diffusion is not limited by cell membranes.

The study of the spatial expression of the segmentation genes fushi tarazu (ftz) and hairy $(h)$ has allowed us to investigate these possibilities. Both of these genes are expressed in seven stripes (out of phase with each other) along the antero-posterior axis (Hafen et al. 1984; Ingham et al. 1985), reflecting the overall blastoderm fate map of the developing embryo. Here we analyze the influence of $e \mathrm{xu}^{-}$on the fate map by monitoring the expression of $f t z$ and $h$ at the RNA and/or protein level. In addition, the homeotic genes Deformed $(D f d)$ and caudal (cad) serve as markers for the anterior and posterior ends, respectively. These results are then compared with embryos derived from tor, trk, and $b c d$ females, using immunolocalization of the $f t z$ protein. Our results show clearly that all of these maternal mutations change the blastoderm fate map but have different effects on the fate map at the anterior and posterior poles. At least exu and bcd exert long-range effects on the fate map.

\section{Results}

\section{Cuticular phenotypes of the maternal-effect mutants}

All the mutants we have used in our study represent a typical phenotype of the respective locus and have been
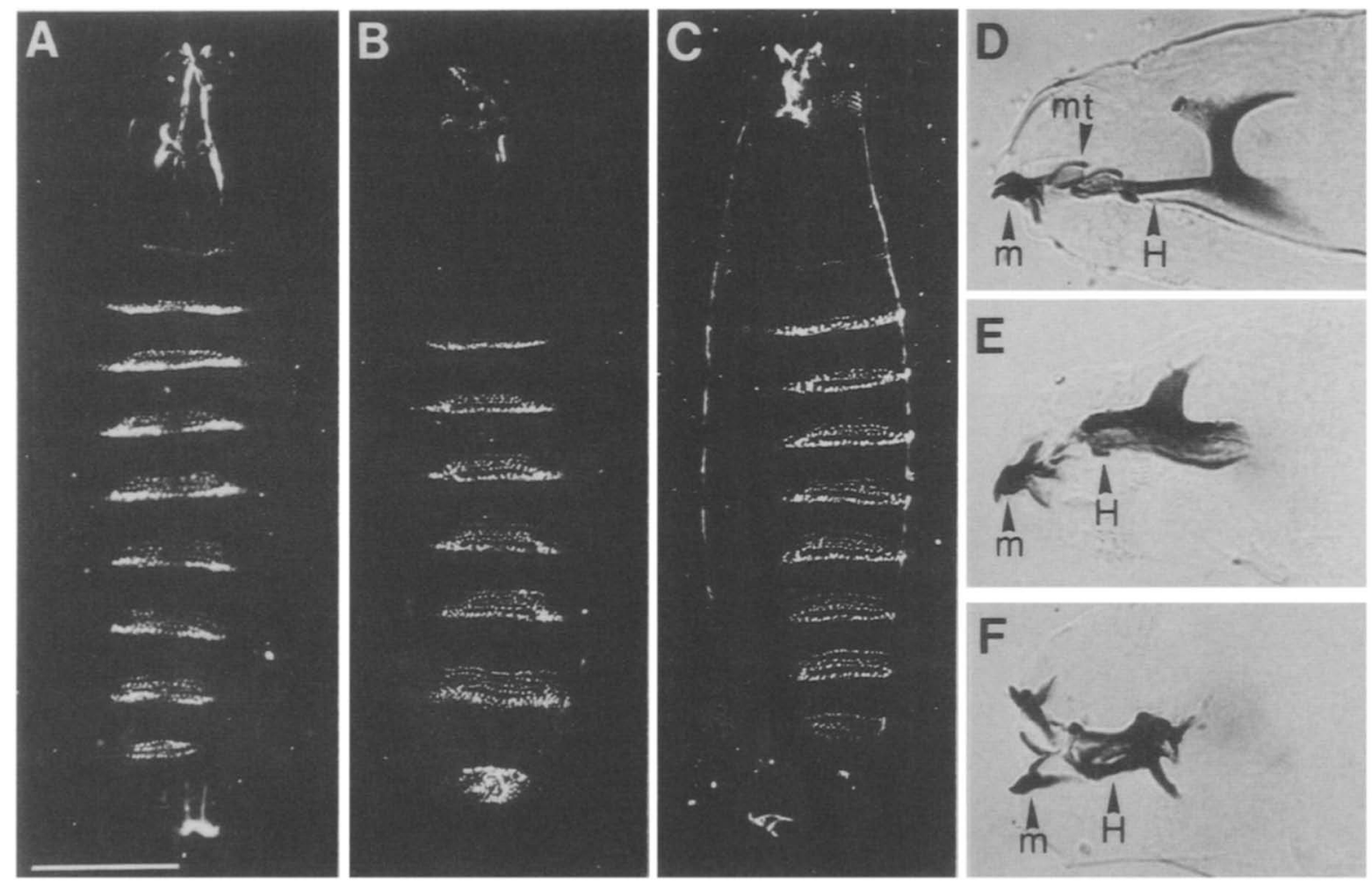

Figure 1. Cuticle preparations of larvae derived from wild-type and mutant females. Embryos from mutant mothers were allowed to develop $24-48 \mathrm{hr}$ at $25^{\circ} \mathrm{C}$ and were mounted according to the protocol of Van der Meer (1977). (A) Wild-type larva. $(B)$ Larva derived from homozygous tor ${ }^{W K}$ mothers. Note that the larva ends with a patch of A7 denticles. $(C)$ Larva derived from transheterozygous exu ${ }^{Q R} / e^{x} u^{P I}$ females. $(D-F)$ Phase-contrast photomicrographs of larval heads: Wild type $(D)$, torso $(E)$, exu $(F)$. (mt) Median tooth, missing in mutants; $(\mathrm{m})$ mouth hooks; $(\mathrm{H})$ H-piece. The horizontal bar represents $0.1 \mathrm{~mm}$ in $A-C$, and $0.05 \mathrm{~mm}$ in $D-F$. 
described in detail elsewhere (Frohnhöfer and NüssleinVolhard 1986; Schüpbach and Wieschaus 1986b|. Here, we briefly outline these descriptions to facilitate the interpretation of our results. Figure 1A shows a larval cuticle pattern of a wild-type first instar larva, and Figure 1C, the cuticular pattern of a typical larva that has developed from an $e x u^{Q R} / e x u^{P I}$ transheterozygote mother. The median tooth (labrum) is absent, and the pharyngeal head skeleton is reduced. All the thoracic and abdominal segments are developed normally and cannot be distinguished from wild type. In embryos derived from tor and trk mothers, the median tooth (labrum) is always absent, and the pharyngeal arms of the mouth skeleton, including the dorsal bridge, are reduced. More posterior head structures are always present. At the posterior end of the same embryos, the structures of the telson (tuft, anal pads, and spiracles with filzkörper), the eighth, and parts of the seventh abdominal segments are always missing, so that tor or trk embryos end posteriorly, with a patch of denticles corresponding to the anterior part of A7 (Fig. 1B; for detailed description, see Schüpbach and Wieschaus 1986b). In Figure 1, D-F, a comparison of the head structures of wild type, exu, and tor larvae is shown. In embryos derived from $b c d$ mothers (strong allele), not only the head structures but also the thorax is missing; they are replaced by a complete telson of opposite polarity. In $b c d$, the anterior abdomen also shows segment defects (for detailed description, see Frohnhöfer and Nüsslein-Volhard 1986). We do not know whether the alleles used in this study /see Materials and
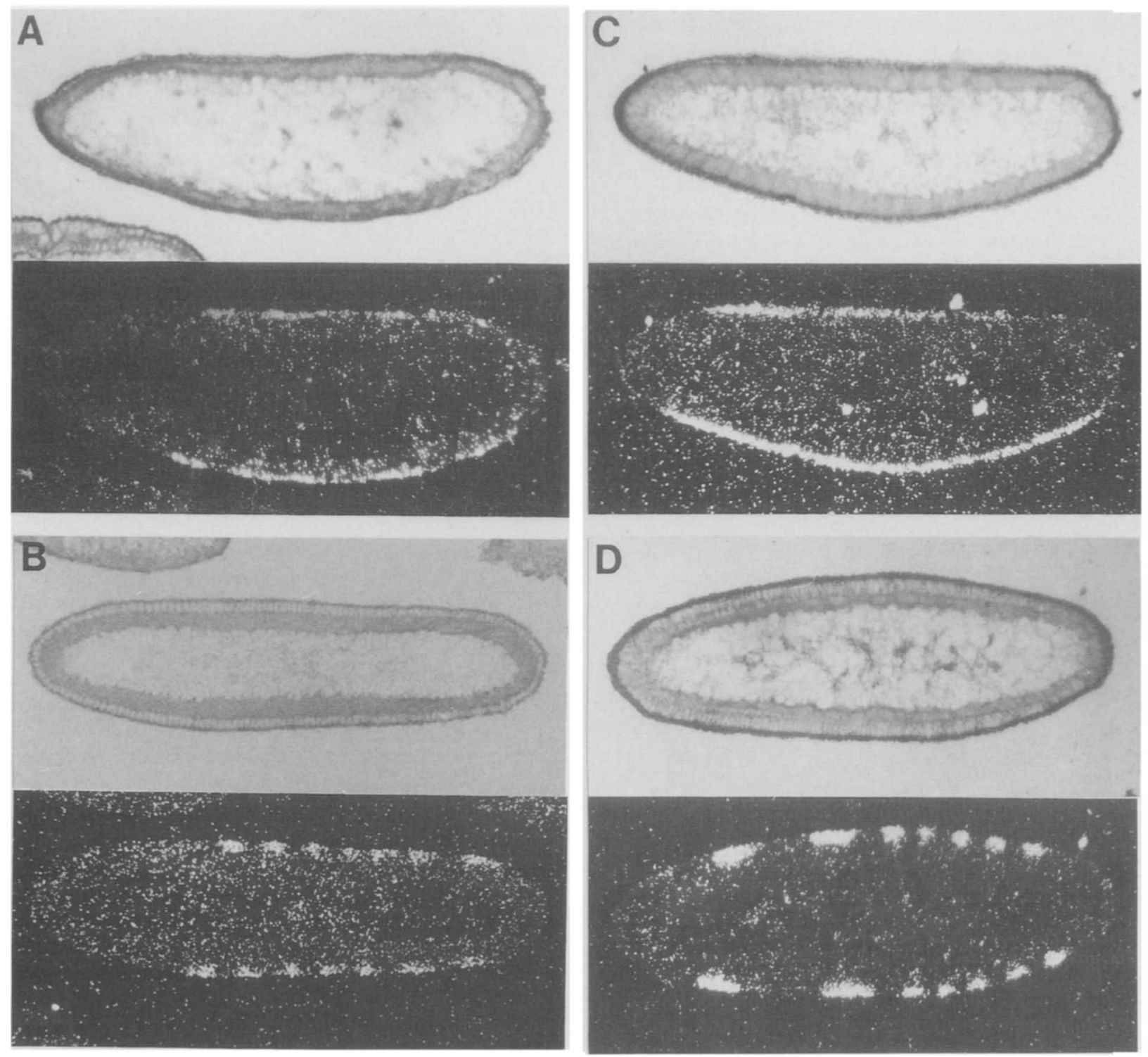

Figure 2. Expression of $f t z$ in wild-type and $e x u^{-}$embryos, as monitored by in situ hybridization. Bright-field and corresponding dark-field photomicrographs show longitudinal sections of embryos from wild-type $(A, B)$ or exu ${ }^{Q R} / e^{e x u^{P I}}$ mothers $(C, D)$. $(A, C)$ Embryos of early stage $14 ;(B, D)$ embryos of late stage 14 . Anterior points to the left. Note the difference between the anterior extension of $f t z$ transcripts in wild-type $(A, B)$ and $e x u^{-}$embryos $(C, D)$. The size of the embryos is $0.5 \mathrm{~mm}$. 
methods) are null alleles; however, they are the strongest alleles available and represent the characteristic phenotype described for each particular locus.

\section{Analysis of exu embryos by monitoring the expression of segmentation genes}

Transcripts from the $f t z$ gene can be visualized one division prior to the formation of the cellular blastoderm (stage 13; see Foe and Alberts 1983). At this stage, the domain of $f t z$ expression is fairly homogeneous and in wild-type embryos is located between $15 \%$ and $65 \%$ egg length (EL; $0 \%$ represents posterior pole of the embryo) (Hafen et al. 1984; Weir and Kornberg 1985; see also Figure 2A). During the following, the last, nuclear division and the beginning of cellularization, a distinctive striped pattern of the $f t z$ expression evolves, resulting by midstage 14 in seven bands of $f t z$ transcripts along the antero-posterior axis (Fig. 2B; Hafen et al. 1984). These bands are roughly evenly sized and spaced, with the exception of the most posterior stripe, which is slightly broader. Using antisera against the $f t z$ protein, seven distinct bands of cells expressing the $f t z$ protein can be detected in late stage-14 embryos along the antero-posterior axis (Fig. 5A; Carroll and Scott 1985).

In embryos derived from exu mothers $\left(e x u^{Q R} / e x u^{P T}\right)$, we detect a dramatic alteration of $f t z$ expression from its very beginning. The domain of $f t z$ expression is enlarged at stage 13 , and transcripts can be detected between $15 \%$ and $85 \%$ EL (Fig. 2C), sometimes extending even more anteriorly to approximately $90 \% \mathrm{EL}$. The final pattern of $f t z$ transcripts is changed as well (Fig. 2D). As in wild type, seven bands are detectable, but they extend at the anterior pole to $85 \% \mathrm{EL}$, and the size and spacing of the two anterior bands are changed markedly. The first band is usually broader (7-9 cells) than in wild type (3-4 cells). The space between the first and second bands is very wide (16-18 cells), and the second band is almost three times wider than in wild type $(\sim 9$ cells $)$. The posterior five bands $(3-7)$ show no dramatic change concerning their size, but they are shifted slightly to more posterior positions than in wild-type embryos (see Fig. 2D). These results are confirmed by in situ hybridization on whole-mount embryos. Figure 3 shows hybridization to a wild-type and an $e x u^{-}$embryo. Very similar stripe patterns can be observed if embryos derived from exu mothers are stained with antisera against the $f t z$ protein (Fig. 5D-F; a wild-type control embryo is shown in Fig. $5 \mathrm{~A})$. In $e x u^{-}$embryos, the most anterior $f t z$ stripe was observed to be of variable size, ranging between 3 and 10 cells (Fig. 5D-F).

To confirm and refine these observations concerning the alterations of the fate map, we have also analyzed the pattern of $h$ by in situ hybridization in $e u^{-}$embryos. In stage-14 embryos, the expression of $h$ is resolved into a pattern of seven bands, between $20 \%$ and $75 \% \mathrm{EL}$, that are roughly out of phase with those of $f t z$, and an additional antero-dorsal patch (0 domain) can be detected (see Fig. 4A; Ingham et al. 1985). In embryos obtained from exu mothers, this pattern clearly reveals changes in the blastoderm fate map similar to those de-
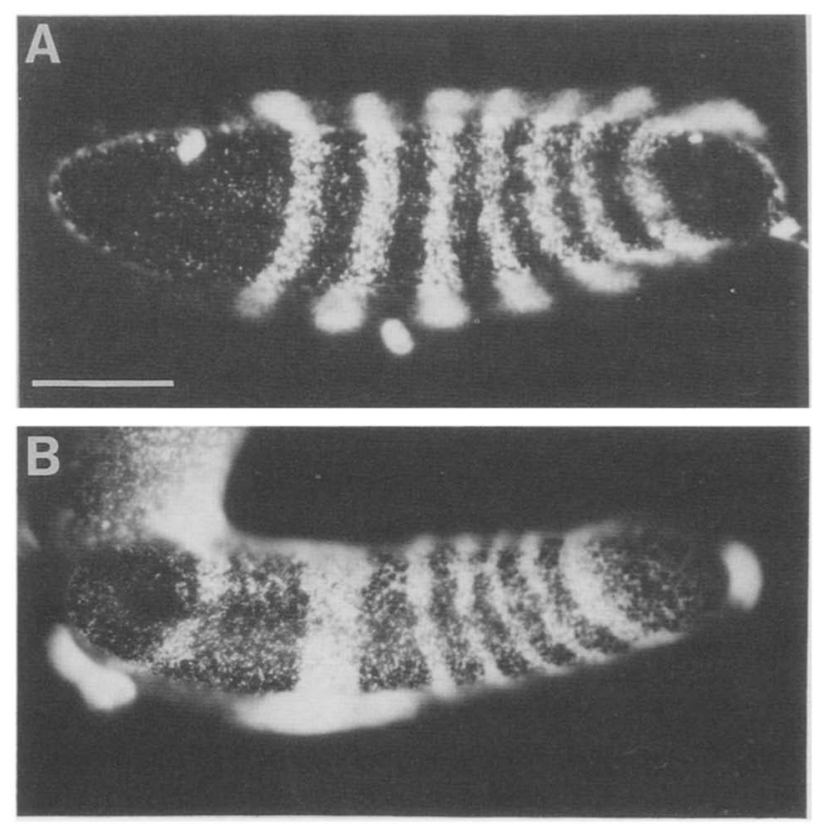

Figure 3. Dark-field photomicrographs of whole-mount embryos analyzed by in situ hybridization. $(A)$ Wild-type wholemount embryo hybridized to a $f t z$ probe. $(B)$ Embryo derived from $e x u^{Q R} / e x u^{P I}$ mothers hybridized to the same probe as in $A$. Anterior points to the left. The bar represents $0.1 \mathrm{~mm}$.

tected by the $f t z$ probe. The seven bands are now expressed between $20 \%$ and approximately $95 \% \mathrm{EL}$, and the 0 domain is absent (Fig. 4B). The most anterior of the seven $h$ bands now extends to $95 \% \mathrm{EL}$, whereas in wildtype embryos, the antero-dorsal patch is present. The following posterior stripes are shifted slightly posteriorly, similar to the $f t z$ stripes.

Comparison of exu with other maternal-effect mutants affecting head development

To compare the changes occuring at the cellular blastoderm in embryos derived from exu mothers to those of embryos of tor or trk mothers, we have monitored $f t z$ protein distribution. The expression of $f t z$ does not extend as far anteriorly in tor- ${ }^{-} t_{r k}^{-}$as in $e \mathrm{xu}^{-}$embryos. In both tor $^{-}$and $t r k^{-}$embryos, the anterior margin of $f t z$ expression lies at approximately $68 \%$ EL (Fig. 5B,C; cf. $e x u^{-}$embryos, Fig. $5 \mathrm{D}-\mathrm{F}$ ), just posterior to the cephalic furrow, which is a marginal change compared to $65 \% \mathrm{EL}$ in the wild type. The following bands look almost identical to the wild-type stripes (cf. Fig. 5C and D with A). Sometimes in tor- embryos, the second band was observed to be one cell broader, and the third band slightly narrower (Fig. 5B). Comparing the anterior $f t z$ pattern in tor ${ }^{-}$and $t^{-} k^{-}$embryos with the wild-type pattern, the changes are minute, certainly not as obvious as those seen in $\mathrm{exu}^{-}$embryos.

However, we also detected differences in the $f t z$ pattern between tor $^{-}$and trk $^{-}$embryos at the posterior end. As mentioned before, bands $2-5$ are almost indistinguishable from the wild-type pattern, but posterior to band 5, tor $^{-}$and $t r k^{-}$embryos vary both from wild type and from each other. In both cases, band 7, the most pos- 

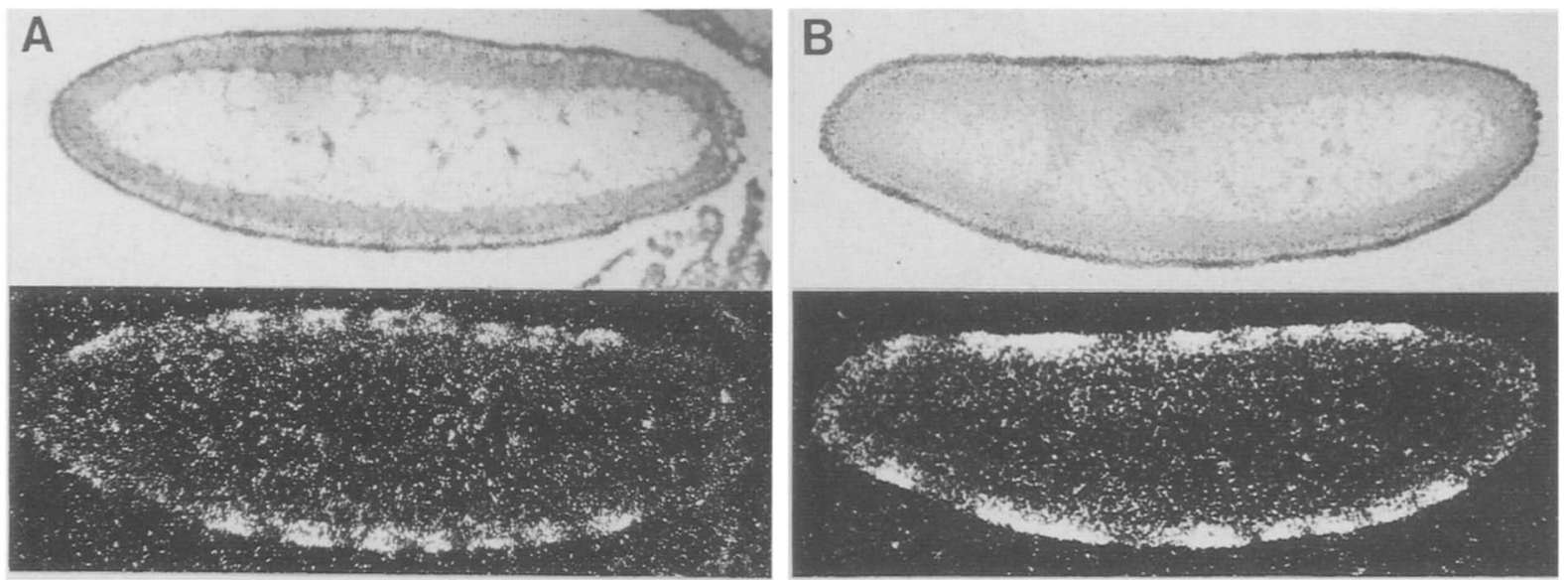

Figure 4. Expression of $h$ in wild-type $(A)$ and $e x u^{-}(B)$ embryos as monitored by in situ hybridization. Bright-field and corresponding dark-field photomicrographs of sagittal sections through stage-14 embryos are shown. Anterior points to the left, and dorsal, up. The size of the embryos is $0.5 \mathrm{~mm}$.
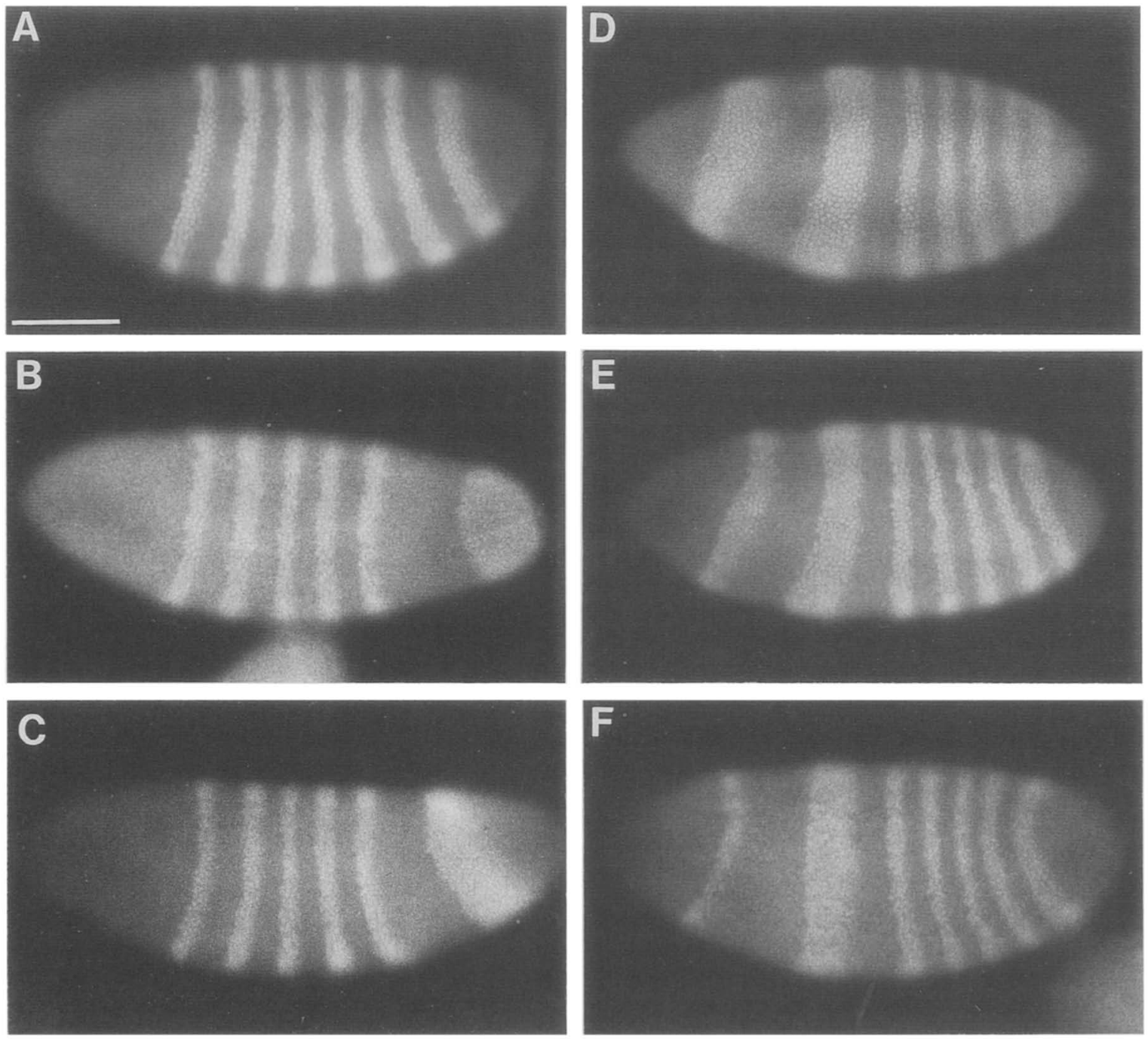

Figure 5. Expression of the $f t z$ protein in embryos at the blastoderm stage derived from transheterozygous tor, $t r k$, and $e x u$ mothers. (A) Wild-type control embryo. (B) Embryo from $t_{0 r}{ }^{W K} /$ tor $^{P M}$ mother. $(C)$ Embryo from $t r k^{R A} / t_{r k} k^{P I}$ mother. Note the difference at the posterior end between $B$ and $C .(D-F)$ Embryos derived from exu $u^{Q R} / e x u^{P I}$ mothers. Note the variability in the anterior $f t z$ band between the $e x u^{-}$embryos. The anterior end of all embryos points to the left, and dorsal is up. The bar represents $0.1 \mathrm{~mm}$. 
terior, is completely absent, which is in agreement with the phenotype of the larval cuticle. Band 6 shows different localization in $t^{-}{ }^{-}$, as compared with $t^{-} k^{-} \mathrm{em}$ bryos. The tor ${ }^{-}$pattern is consistent from embryo to embryo. Band 6 resembles a cap at the posterior pole (except for pole cells) and has its anterior margin at approximately $17 \%$ EL (Fig. 5B). However, in embryos derived from trk mothers, the anterior border of band 6 begins at approximately $22 \% \mathrm{EL}$ and extends to $10 \% \mathrm{EL}$. The band is about $8-10$ cells wide (narrower than in tor embryos), and there is no $\mathrm{ftz}$ expression in the most posterior part of the embryo. In addition, there is also some variability among individual tor and trk embryos. Very similar results have been obtained by staining for $\beta$-galactosidase ( $\beta$-Gal) to monitor $f t z$ expression, using the upstream regulatory sequences of $f t z$ to control $\beta$-Gal activity (Y. Hiromi and W.J. Gehring, unpubl.; see also next section).

The most extensive anterior deletions (and duplications) of the maternal-effect mutants analyzed are caused by mutations at the $b c d$ locus. In $b c d^{-}$embryos, the changes in $f t z$ protein accumulation are very prominent (Fig. 6). Only five to six $f t z$ bands can be observed in these mutant embryos, and only the most posterior stripe has approximately the same size as in wild type, but it is shifted, to some extent, anteriorly as well. The next two anterior bands (most likely corresponding to bands 5 and 6 in wild type) are clearly shifted anteriorly by $10-15 \%$ so that the stripe corresponding to band 5 in wild type is located around $40-45 \% \mathrm{EL}$ in $b c d^{-}$embryos (Fig. 6). Between approximately $55 \%$ and $73 \% \mathrm{EL}$, we always observe one broad region of $f t z$ expression (13-15 cells wide); this could correspond to a broadened band 3, sometimes fused with band 4 (see below). Most likely, we do not detect any $f t z$ expression that corresponds to bands 1 and 2 in wild type, which is in agreement with the lack of thoracic structures in the larval cuticle on embryos derived from $b c d$ mothers carrying a strong mutant allele (Frohnhöfer and Nüsslein-Volhard 1986). In a fraction of the embryos, an additional $\mathrm{ftz}$ stripe (two to three cells wide) can be resolved between this broad region and the posterior three $f t z$ bands (Fig. 6A), which can be partially missing (Fig. 6B) or completely absent (Fig. 6C). At the anterior end of $b c d^{-}$embryos, we detect a new $\mathrm{ftz}$ band that most likely corresponds to a duplicated most posterior stripe.

\section{$\mathrm{ftz}$ expression in exu double mutants with the zygotic gap loci}

It has been shown that $6 \mathrm{~kb}$ of $f t z$ upstream regulatory sequences are sufficient to generate the $f t z$ pattern when fused to the bacterial $\beta$-Gal gene and transferred by P-element transformation into the Drosophila genome. Activity staining for $\beta$-Gal in this fly strain shows a "normal" ftz pattern (Hiromi et al. 1985). Crossing the transformed lines into a mutant background then makes it possible to analyze the $f t z$ pattern in particular mutants (Y. Hiromi and W.J. Gehring, in prep. and unpubl.).

We have used this approach to analyze the effects of maternal and zygotic gap genes in $e x u^{-}$embryos on $f t z$
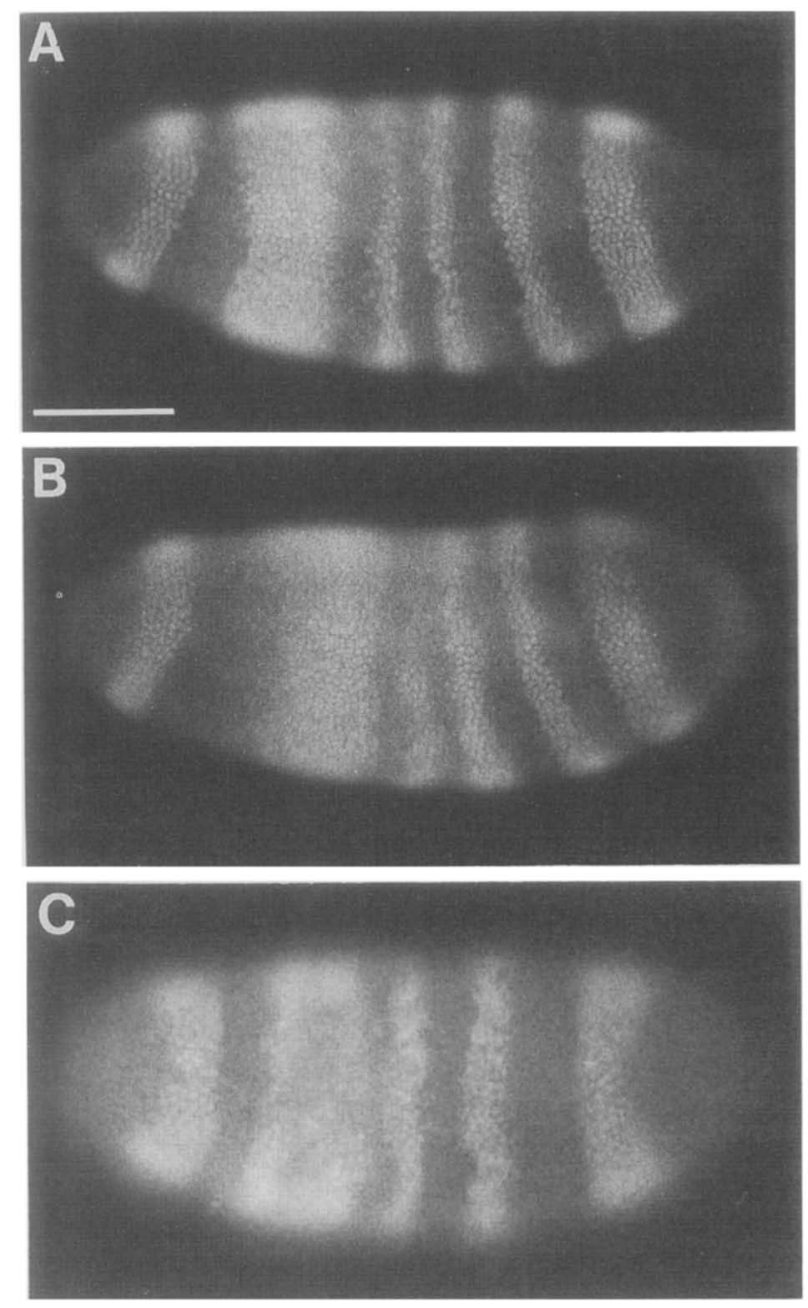

Figure 6. $f t z$ protein localization in embryos derived from homozygous $b c d^{E 1}$ mothers. Note the variability in the $f t z$ pattern in the middle of the embryo among the three individuals shown in $A, B$, and $C$. Anterior points to the left, and dorsal, where visible, is up.

expression. Two maternal-effect genes of the grandchildless-knirps group, namely staufen (stau) and vasa (vas) (Schüpbach and Wieschaus 1986b), and the zygotic gap genes hunchback ( $h b$; Lehmann and Nüsslein-Volhard 1987) and knirps (kni; Nüsslein-Volhard and Wieschaus 1980) have been analyzed in combination with exu $u^{-}$mutants. stau ${ }^{-}$and vas $^{-}$embryos abolish (almost) completely the development of abdominal structures and, in addition, in stau- embryos, anterior head structures are also deleted (Schüpbach and Wieschaus 1986b). $h b$ is mainly required for correct gnathal and thoracic development and for formation of abdominal segments A7-A8 (for detailed phenotypic description, see Lehmann and Nüsslein-Volhard 1987) and kni is required for the development of abdominal segments A2-A7 (Nüsslein-Volhard and Wieschaus 1980).

The $\beta$-Gal activity staining pattern in $e x u^{-}$embryos shows the same alterations in relation to the wild-type pattern as observed by in situ hybridization and/or anti- 
body detection (Fig. 7B; cf. $\beta$-Gal staining in wild-type embryos, Fig. 7A).

The patterns observed in exu,kni and exu,hb double mutants demonstrate clearly that both $h b$ and $k n i$ have an additive effect to exu on $f t z$ expression, leading es- sentially to the same changes of the $f t z$ pattern in $e x u^{+}$ and $e x u^{-}$backgrounds, except for the general shift toward the anterior pole of the two anterior bands in $e^{-}$ embryos (Fig. 7D,F). The $\mathrm{kni}^{-}$pattern (stripes 3-6, fused to one broad band) and the $h b^{-}$pattern (stripes $1-3$ and

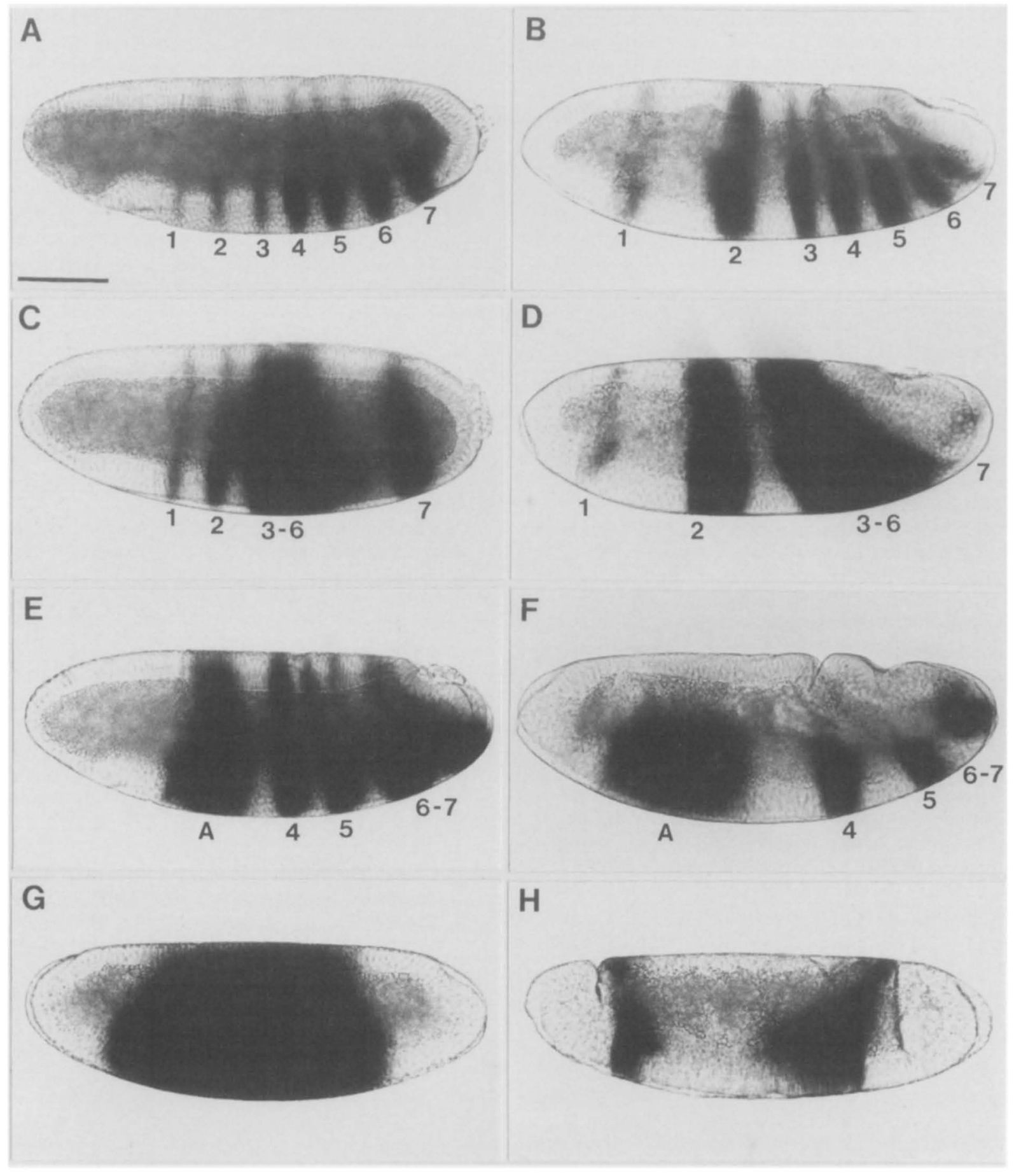

Figure 7. Expression of $\beta$-Gal under $f t z$ control elements in mutant embryos. The embryos are all in gastrula stages; anterior always points to the left, and dorsal, up. $(A)$ Wild-type control embryo. The $f t z$ stripes are numbered from anterior to posterior $1-7$. $(B)$ Embryo derived from $e x u^{Q R} / e x u^{P I}$ mother. $(C)$ Homozygous kni ${ }^{I I D 48}$ embryo from heterozygous balanced parents. $(D)$ Embryo derived from exu ${ }^{Q R} / e x u^{P I}$ mother, having a $k n i^{I I D 48} / k_{n i} i^{I D 48}$ genotype. $(E)$ Homozygous $h b^{14 F 21} / h b^{14 F 21}$ embryo from heterozygous balanced parents. $(F)$ Embryo derived from exuQR/exu ${ }^{P I}$ mothers having a $h b^{14 F 21}$ genotype. $(B-F)$ The $f t z$ stripes are numbered according to $A$. $(E, F)$ : anterior patch, $(\mathrm{A})$, is located where stripes $1-3$ are found in wild-type embryos. $(G)$ Embryo derived from $e x u^{Q R} / e^{e x u^{P I}}$ stau ${ }^{H L /}$ stau ${ }^{H L}$ mother. $(H)$ Embryo derived from $e x u^{Q R} / e x u^{P I} ; v a s^{P D} / v a s^{P D}$ mother. The horizontal bar represents $0.1 \mathrm{~mm}$. 
6-7, fused to broad regions of expression) remain the same (Fig. 7C,E, respectively). Very similar results for the two zygotic mutants have been published previously with antibody staining (Carroll and Scott 1986). However, in double mutants of exu and stau (Fig. 7G) and exu and vas (Fig. $7 \mathrm{H})$, the $f t z$ staining patterns cannot be explained by either additive or epistatic effects. Embryos derived from exu,stau females show $\mathrm{ftz}$ expression all over the embryo between $20 \%$ and $80 \%$ EL (Fig. $7 \mathrm{G}$ ), and in embryos derived from exu,vas mothers, $f t z$ is expressed in two patches at 20-30\%, and $70-80 \%$ EL (Fig. $7 \mathrm{H})$. Using the same constructs in double mutants with tor and stau or tor and vas, the $\beta$-Gal staining patterns under $f t z$ control elements can be explained by an additive effect (Y. Hiromi and W.J. Gehring, unpubl.). Similar effects for both types of double mutants have been observed by the analysis of the larval cuticle (Schüpbach and Wieschaus 1986b).

\section{Expression of Dfd and cad in exu- embryos}

To analyze the changes at the anterior end in embryos derived from exu females, namely the extent of the reduction of head structures and of the posterior duplication, we also used $D f d$, a homeotic gene required for head development, and cad, a homeotic gene expressed in the most posterior abdominal region and in the posterior midgut, as probes for in situ hybridization.

Figure 8 shows in situ distribution of $D f d$ transcripts in embryos derived from wild-type and exu mothers. In wild-type embryos, $D f d$ hybridizes to one band of approximately six cells at the position of the cephalic furrow (Fig. 8A; McGinnis et al. 1984; Chadwick and McGinnis 1987). This partially overlaps with the anlagen of the mandibular and maxillary segments. In embryos derived from exu females, the band of $D f d$ expression is shifted toward the anterior pole and lies at about 90-95\% EL (Fig. 8B), showing that the anlagen for the posterior head segments lie much more anteriorly than in wild type. This shift persists throughout the embryonic development of $e x u^{-}$embryos (data not shown).
Figure 9 shows cad RNA localization during early and late embryogenesis. cad RNA distribution during early embryogenesis is not affected in embryos derived from $e x u$ mothers. The RNA forms an antero-posterior gradient in late syncytial blastoderm, as seen in wild-type embryos (Fig. 9A) (Levine et al. 1985; Mlodzik et al. 1985; Mlodzik and Gehring 1987). After cellularization, transcripts are detected in one posterior band (four to five cells) at the very end of the germ band, as in wildtype embryos (Fig. 9B). At the germ-band extension stage, cad transcripts can be detected not only in ectodermal tissue, the most posterior abdominal segment and the hindgut primordia, but also in endodermal tissue, the posterior midgut rudiment (Levine et al. 1985; Mlodzik et al. 1985). In embryos derived from exu females, the endodermal cad expression starts to be duplicated at the anterior pole during the same developmental stage and becomes more pronounced after germband retraction. Figure 9D shows an $e x u^{-}$embryo about 14 hours after fertilization, where two domains of cad RNA in the endoderm can be detected. A comparison to a wild-type embryo of approximately the same stage demonstrates this abnormal duplication in the anterior part (Fig. 9C,D).

\section{Conclusions}

It has been shown previously that maternal mutants of the grandchildless-knirps group, which affect the formation of the abdomen, have similar abdominal deletions but show very different alterations of the $f t z$ pattern (Carroll et al. 1986). Here we demonstrate that mutations in the maternal-effect genes, exu, tor, trk, and bcd, change the fate map at the blastoderm stage. The phenotypic deletions in the larval head in $e x u^{-}$embryos and tor- or trk $^{-}$embryos are similar, although not identical; the observed changes in the anterior half of the blastoderm fate map, however, are completely different. tor ${ }^{-}$ and $t^{-} k^{-}$embryos show only a marginal anterior shift of the most anterior $f t z$ band from $65 \%$ EL in wild type to

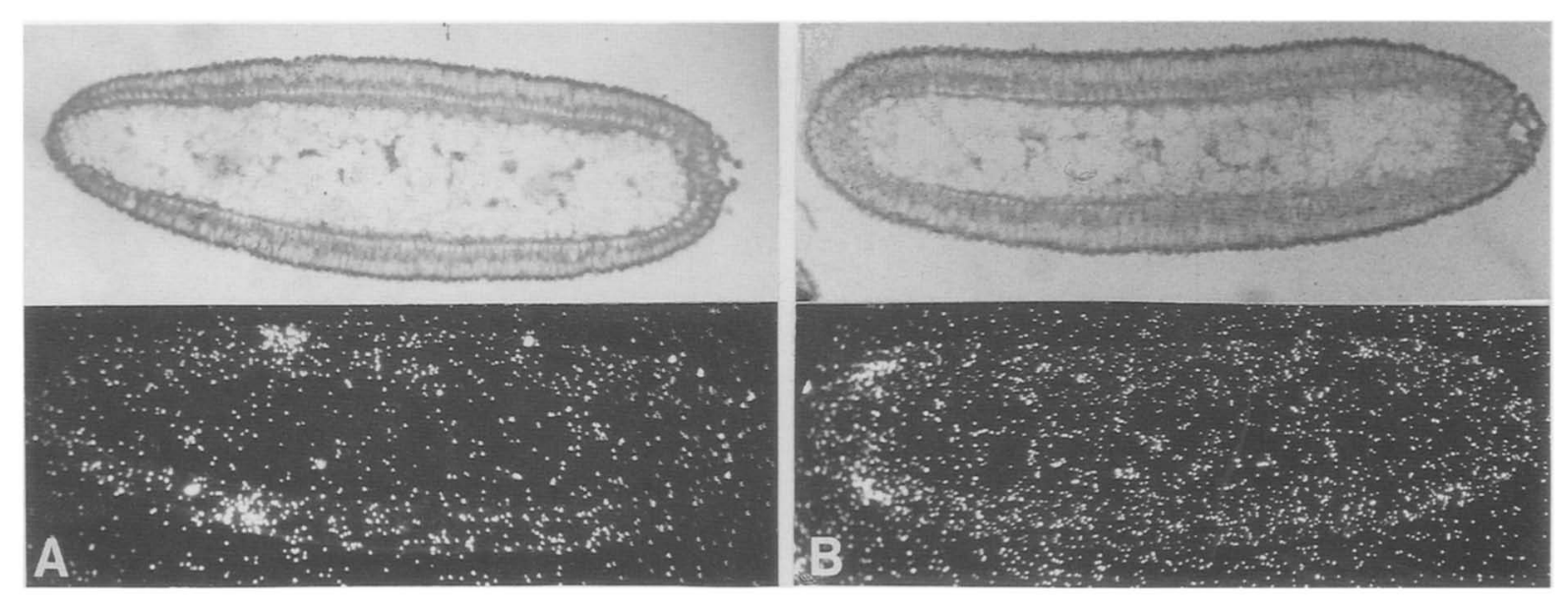

Figure 8. Localization of $D f d$ transcripts in blastoderm embryos. Bright- and corresponding dark-field photomicrographs of longitudinal sections are shown. $(A)$ Wild type. $(B)$ Embryo from $e x u^{Q R} / e x u^{P I}$ mother. Anterior points to the left. The size of the embryos is $0.5 \mathrm{~mm}$. 
$68 \% \mathrm{EL}$ in the mutants; exu leads to a shift up to $85-90 \%$ EL. This clear difference is not obvious from the larval phenotype but is certainly more obvious by comparing gastrulation patterns at the anterior end (Schüpbach and Wieschaus 1986b). Absence of exu activity or gene product(s) shows a more pronounced longrange effect on the blastoderm fate map than the other two genes, that is, the expression of $D f d$ is effected severely in $e x u^{-}$embryos (Fig. 8). exu activity also seems to be required directly or indirectly for the induction of an anterior midgut invagination. Schüpbach and Wieschaus (1986b) have shown that a posterior midgut invagination replaces the anterior one in $e x u^{-}$embryos, and in Figure 9 we show that cad is expressed not only in
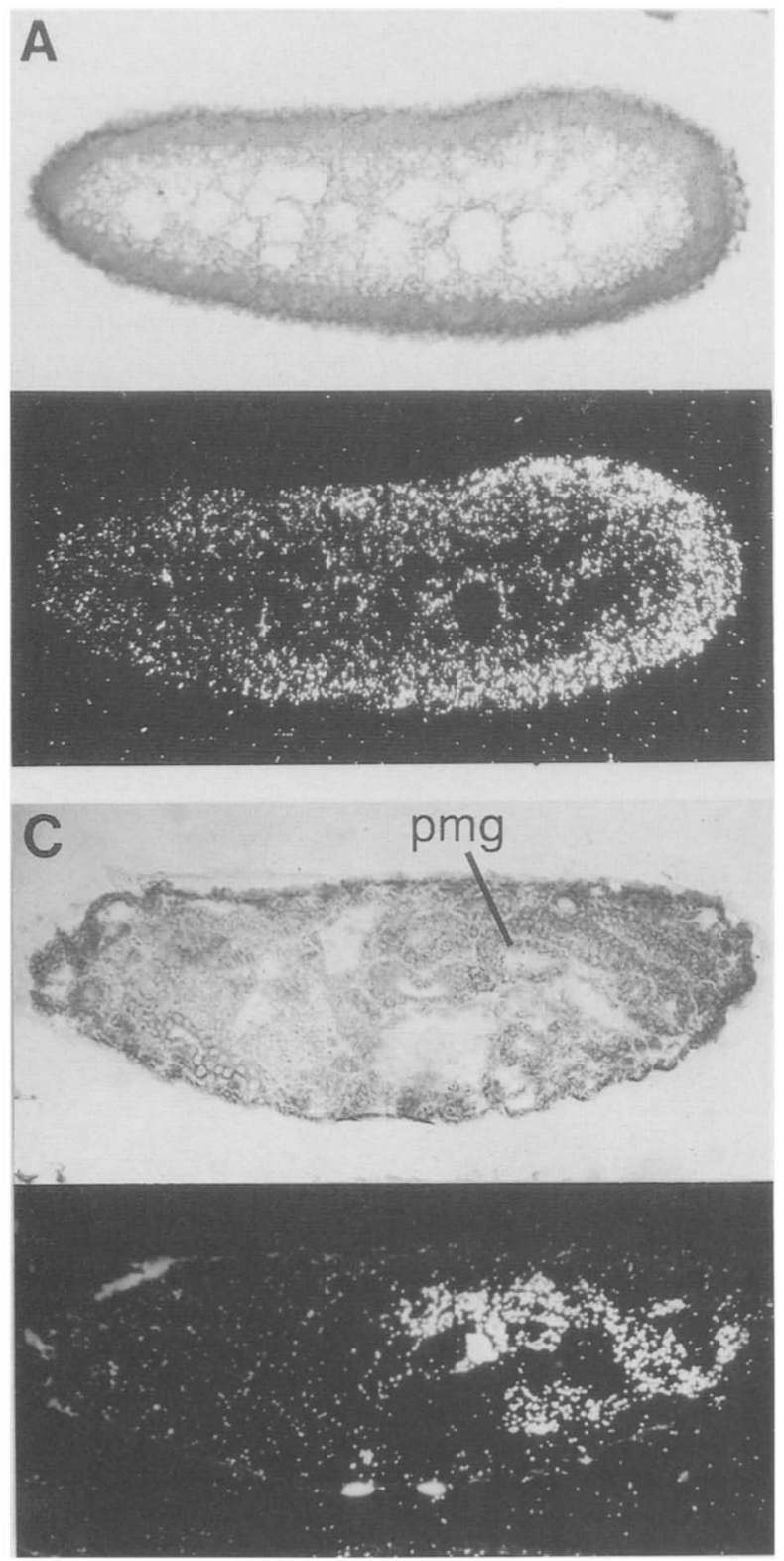

posterior regions (in the ecto- and endoderm) of $e x u^{-}$ embryos but in the anterior endoderm as well.

The long-range effects on the blastoderm fate map in $e x u^{-}$embryos can be summarized as follows: Posterior head and thoracic structures extend more anteriorly, almost to the very anterior end of the embryo; in contrast, the abdominal pattern $\mid \mathrm{Al}$ and more posterior structures) is compressed in the posterior half of the embryo. In some embryos, this compression of abdominal structures leads to the lack of resolution of the posterior $\mathrm{ftz}$ bands, for example, bands 6 and 7 are partially fused (Fig. 5D). This finding correlates with the observation that minor abdominal defects can be found in some $e x u^{-}$ embryos at the end of embryogenesis /Schüpbach and
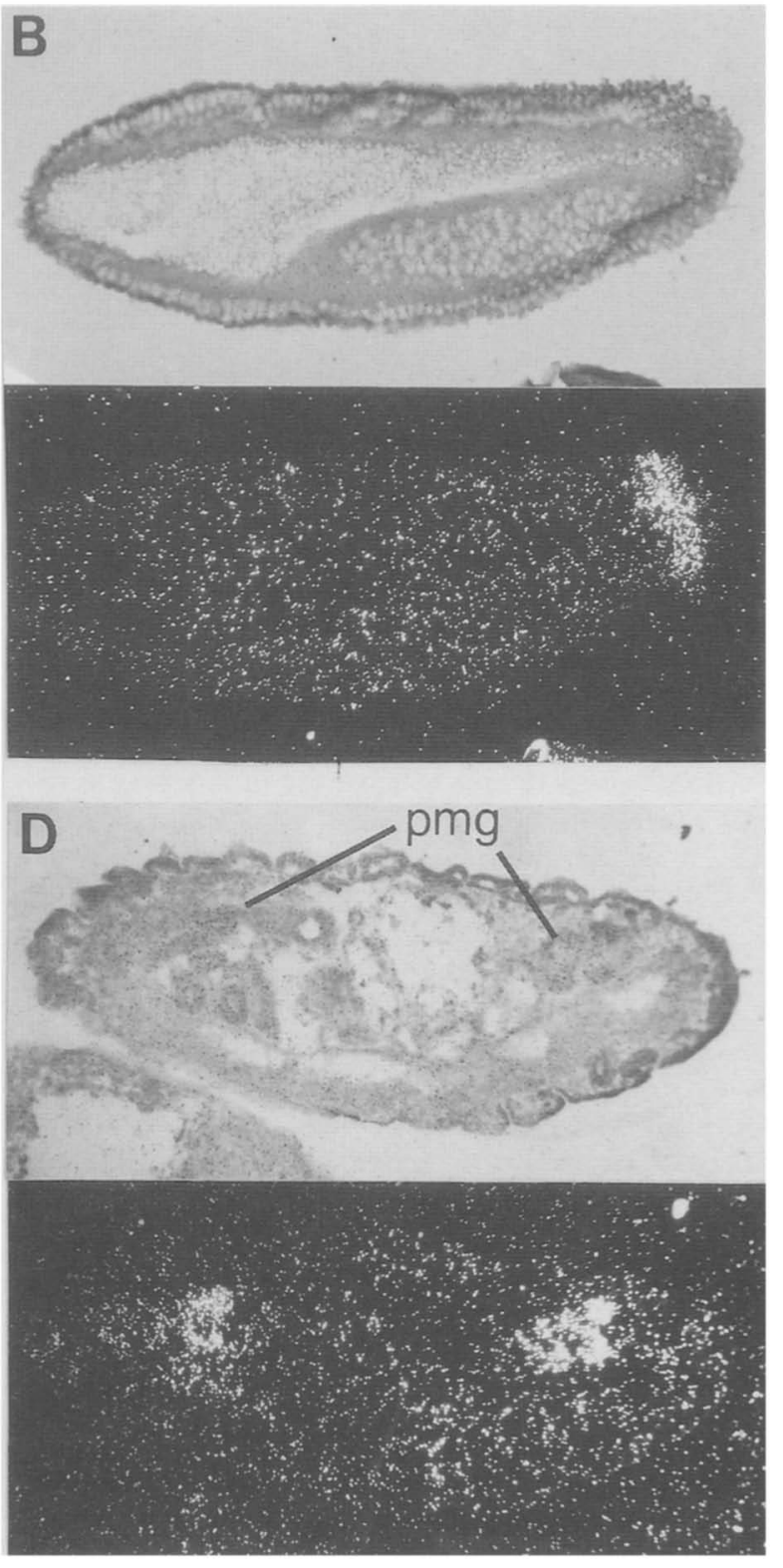

Figure 9. Distribution of cad transcripts in embryos derived from exu mothers. Bright-field and corresponding dark-field photomicrographs are shown. $(A)$ Stage-14 embryo. $(B)$ Early gastrula. $(C, D)$ Embryos after germ-band retraction $(\sim 14 \mathrm{hr}$ after fertilization). $(C)$ Wild-type control embryo. (D) exu- embryo. Anterior points to the left, and dorsal, up. The size of the embryos is $0.5 \mathrm{~mm}$. (pmg) Posterior midgut. 
Wieschaus 1986b). The type of long-range alterations of the fate map in $e x u^{-}$embryos might suggest that exu could be involved in maintaining or localizing anterior determinants or gene product(s) at the anterior end. In the $e u^{-}$mutant this would not be possible any more, so that this (these) product(s) can diffuse posteriorly, being present in a broader region of the embryo but at lower concentrations, which might be responsible for extension of thoracic values and compression of the abdominal region. Although we do not detect clear differences in cad expression at the RNA level between wild-type and $e u^{-}$embryos prior to germ-band extension (Fig. 9), we do find some differences for the cad protein distribution in $e x u^{-}$embryos (M. Mlodzik and W.J. Gehring, in prep.l, which reflect and confirm the alterations of $f t z$ protein distribution. These effects were not observed in embryos derived from trk or tor mothers.

The phenotypic analysis of $b c d^{-}$embryos shows the most dramatic changes in the overall body plan of the embryo, particularly in the anterior region (Frohnhöfer and Nüsslein-Volhard 1986), and in parallel, the ftz pattern alterations are also the most severe. Not only are there five to six $\mathrm{ftz}$ bands instead of seven, but the anterior band in $b c d^{-}$embryos is also a duplicated posterior one. This can also be visualized with cad antibody staining (M. Mlodzik and W.J. Gehring, in prep.), where the telson duplication can be detected as early as the cellular blastoderm in the form of a second band of cad protein close to the anterior pole. The differences we observe in the $f t z$ staining pattern within $b c d^{-}$embryos can be aligned with the detected phenotypic defects; both show deletions or fusions of anterior abdominal segments (Frohnhöfer and Nüsslein-Volhard 1986) and the fragment or absence of a sixth $f t z$ band in the abdominal region (Fig. 6). In addition, embryos derived from $b c d$ females not only show duplication of posterior ectoderm at the anterior pole but also exhibit a very pronounced long-range effect in the abdomen, shifting almost all remaining $f t z$ bands anteriorly. Thus, the lack of $b c d^{-}$activity allows an anterior shift or expansion of abdominal segments, suggesting that in addition to specifying anterior structures, $b c d^{+}$activity also inhibits development of abdominal segments (structures) in the anterior half of the embryo (Frohnhöfer and Nüsslein-Volhard 1986). The finding that the bcd gene shares homology to the homeo box (Frigerio et al. 1986) suggests its action being rather direct in the control of development of the head and anterior structures.

The double mutant analysis of exu with the zygotic gap genes, for example, $h b$ and $k n i$ (Fig. 7C-F), indicates that these genes act independently of exu on the altered fate map (cf. Fig. 7C and E with D and F). However, this is not the case in double mutants of exu with genes from the maternal grandchildless-knirps group, stau, or vas. The staining patterns of these double mutants show neither epistatic nor additive effects but, rather, reflect synergistic interactions between these genes /Fig. 7G and $\mathrm{H})$.

To our surprise, we also detected differences in the posterior $f t z$ pattern between embryos derived from tor and trk females, although analysis of the larval cuticle shows no differences between tor $^{-}$and $t r k^{-}$embryos. In both mutants, the embryos end with a patch of denticles corresponding to A7 (Schüpbach and Wieschaus 1986b; Fig. 1B), and in both mutants the most posterior wildtype $f t z$ band (7) is completely absent. The sixth $f t z$ band in wild-type embryos overlaps with the border between A6 and A7, being expressed in posterior A6 and anterior A7, corresponding approximately to parasegment 12 (Martinez-Arias and Lawrence 1985). This expression can be correlated with the pattern in tor embryos, where the sixth $f t z$ band extends to the very posterior end. However, in embryos derived from trk mothers, the most posterior end $(\sim 10 \%)$ of the embryo does not express $f t z$, and the sixth band is anterior to the position in tor- embryos (Fig. 5), which would lead one to expect the formation of a complete denticle band in A7 and possibly naked cuticle at the posterior end in $t r k^{-}$embryos. This, however, has not been observed and suggests that secondary alterations occur after the blastoderm stage.

So far, all the maternal mutants analyzed (Carroll et al. 1987; this paper; Y. Hiromi and W.J. Gehring, unpubl.) show a changed $f t z$ pattern at the blastoderm stage. However, these pattern changes are not the same, even if the mutant cuticular phenotypes are very similar or identical, indicating that perhaps the same or similar phenotypes can arise through mutations in different molecular processes. Cloning and molecular analysis of these maternally active genes should provide more information on their interactions with the zygotically active genes, like $f t z$, and also on interactions between the maternal genes themselves. Our observations on $e u^{-}$ and $b c d^{-}$embryos clearly show that long-range interactions take place between the maternal gene products that specify the spatial coordinates of the egg.

\section{Materials and methods}

Fly stocks and DNA clones

Mutant flies were kept at $25^{\circ} \mathrm{C}$ on standard Drosophila food. We have used two alleles of exu, namely exu $u^{Q R}$ and $e x u^{P I}$, two of $t o r, t^{\prime}{ }^{W K}$ and $t^{2} r^{P M}$, and two of $t r k, t r k^{R A}$ and $t r k^{P I}$, all generously provided by T. Schüpbach and E. Wieschaus (1986b), and the allele $b c d^{E 1}$ for $b c d$, kindly provided by C. Nüsslein-Volhard (Frohnhöfer and Nüsslein-Volhard 1986). In addition, for double mutants with exu, we have used the stau and vas alleles, stau ${ }^{H L}$ and $v a s^{P D}$ (Schüpbach and Wieschaus 1986b); the $h b$ allele, $h b^{14 F 21}$ (Lehmann and Nüsslein-Volhard 1987); and the knirps allele, knil ${ }^{I I D 48}$ (Nüsslein-Volhard and Wieschaus 1980).

The following DNA clones have been used for in situ hybridization: cDNA clone pSPF1 for $f t z$; D2P8, a cDNA clone of $h$ (kindly provided by D. Ish-Horowicz); p99 for Dfd (McGinnis et al. 1984); and pSC335 for cad (Mlodzik et al. 1985).

\section{Preparation of embryos and in situ hybridization}

Embryos were collected from transheterozygous mothers of the two exu alleles for the appropriate time at $25^{\circ} \mathrm{C}$, washed, and dechorionated in $3 \%$ sodium-hypochlorite for $2-3 \mathrm{~min}$. Young embryos, 0-8 hr old, were prefixed, demembranated, postfixed, and embedded, as described by Akam and Martinez-Arias 
(1985). Frozen sections were prepared, pretreated prior to hybridization, and hybridized, as described by Hafen et al. (1983). Probes for in situ hybridization were nick-translated with ${ }^{3} \mathrm{H}$ labeled nucleotides, according to Hafen et al. (1983).

For in situ hybridization to whole-mount embryos, embryos were collected, washed, and dechorionated, as described above. Embryos were then fixed, and the vitelline membrane was removed, as described by Mitchison and Sedat (1983). Subsequently, embryos were fixed in $4 \%$ paraformaldehyde in PBS for $20 \mathrm{~min}$, washed twice for $5 \mathrm{~min}$ in PBS, and pretreated for hybridization, as described for frozen sections (Hafen et al. 1983), except that heat treatment $\left(70^{\circ} \mathrm{C}\right.$ in $2 \times$ SSC) was omitted and all washes were performed in PBS. Embryos were hybridized in an Eppendorf tube on a turning wheel at $37^{\circ} \mathrm{C}$ in the hybridization buffer, as described by Hafen et al. (1983), for 16-20 hr, washed for $6-8 \mathrm{hr}$ at $37^{\circ} \mathrm{C}$ in PBS (on turning wheel), and dehydrated by washing several times in ethanol. Following dehydration, embryos were air-dried on subbed slides for approximately $2 \mathrm{hr}$, covered with emulsion, and exposed for 3-4 weeks.

\section{Immunofluorescence and $\beta$-Gal activity assay on whole-} mount embryos

Embryos were collected from transheterozygous mutant mothers for the appropriate time at $25^{\circ} \mathrm{C}$, washed, and dechorionated, as described for the in situ hybridization. They were then fixed and devitellinized, as described by Deguin et al. (1984), and permeabilized in a PBS solution containing $0.05 \%$ each of Triton X-100, NP-40, deoxycholate (DOC), Saponin, and $2 \mathrm{mg} / \mathrm{ml}$ bovine serum albumin (BSA). The antiserum was diluted into PBS containing 5\% swine serum, $0.1 \%$ Triton X-100, and $0.02 \%$ sodium azide. One hundred microliters of a $1: 50$ or $1: 100$ dilution were reacted with 100-200 embryos for $2 \mathrm{hr}$ at room temperature or $4^{\circ} \mathrm{C}$ overnight. All washes and antibody incubations were performed in this solution. After incubation with the primary antibody, the embryos were washed for 90 min at room temperature, incubated with a $1: 50$ dilution of a swine-anti-rabbit serum coupled to FITC (purchased from Dakopatts) for $90 \mathrm{~min}$, and washed again for $90 \mathrm{~min}$ at room temperature. After the final wash, embryos were mounted in Gelvitol (Rodriguez and Deinhardt 1960). Polyclonal antisera against the $f t z$ full-length protein, expressed and purified from Escherichia coli, were raised in rabbits (H.M. Krause and W.J. Gehring, in prep.).

For $\beta$-Gal activity staining, embryos were collected, pretreated, and fixed, as described by Hiromi et al. (1985), and staining was performed using staining solution as described by Simon et al. (1985).

\section{Acknowledgments}

We are very grateful to Trudi Schüpbach, Eric Wieschaus, and Christiane Nüsslein-Volhard for generously providing us with the mutant stocks, and David Ish-Horowicz for providing the $h$ probe. We thank Greg Gibson for help with cuticle preparations and comments on the manuscript and Erika Wenger-Marquardt for the efficient typing of it. This work was supported by the Swiss National Science Foundation and the Kantons of Basel. H.M.K. was supported by a grant from the Natural Sciences and Engineering Research Council of Canada; C.M. De M., by the Bourse détudes de France.

\section{References}

Akam, M.E. and A. Martinez-Arias. 1985. The distribution of Ultrabithorax transcripts in Drosophila embryos. EMBO $J$. 4: $1689-1700$.
Anderson, K.V. and C. Nüsslein-Volhard. 1984. Information for the dorsal-ventral pattern of Drosophila is stored as maternal mRNA. Nature 311: 223-227.

Boswell, R.E. and A.P. Mahowald. 1985. Tudor, a gene required for assembly of the germ plasm in Drosophila melanogaster. Cell 43: 97-104.

Bull, A.L. 1966. Bicaudal, a genetic factor which affects the polarity of the embryo in Drosophila melanogaster. J. Exp. Zool. 161: 221 .

Carroll, S.B. and M.P. Scott. 1985. Localization of the fushi tarazu protein during Drosophila embryogenesis. Cell 43: 47-57.

Carroll, S.B. and M.P. Scott. 1986. Zygotically active genes that affect the spatial expression of the fushi tarazu segmentation gene during early Drosophila embryogenesis. Cell 45: $113-126$.

Carroll, S.B., G.M. Winslow, T. Schüpbach, and M.P. Scott. 1986. Maternal control of Drosophila segmentation gene expression. Nature 323: 278-280.

Chadwick, R. and W. McGinnis. 1987. Temporal and spatial distribution of transcripts from the Deformed gene of Drosophila. EMBO I. 6: 779-789.

Chan, L.-N. and W.J. Gehring. 1971. Determination of blastoderm cells in Drosophila melanogaster. Proc. Natl. Acad. Sci. 68: 2217-2221.

Deguin, R., H. Saumweber, and J.W. Sedat. 1984. Proteins shifting from the cytoplasm into the nuclei during early embryogenesis of Drosophila melanogaster. Dev. Biol. 104: $37-48$.

Foe, V.E. and B.M. Alberts. 1983. Studies of nuclear and cytoplasmic behaviour during the five mitotic cycles that precede gastrulation in Drosophila embryogenesis. J. Cell Sci. 61: $31-70$.

Frigerio, G., M. Burri, D. Bopp, S. Baumgartner, and M. Noll. 1986. Structure of the segmentation gene paired and the Drosophila PRD gene set as part of a gene network. Cell 47: 735-746.

Frohnhöfer, H.G. and C. Nüsslein-Volhard. 1986. Organization of anterior pattern in the Drosophila embryo by the maternal gene bicoid. Nature 324: 120-125.

Garcia-Bellido, A. 1975. Genetic control of wing disc development in Drosophila. In Cell patterning, Ciba Foundation Symposium 29, p. 61. Elsevier, Amsterdam.

Hafen, E., M. Levine, R.L. Gerber, and W.J. Gehring. 1983. An improved in situ hybridization method for the detection of cellular RNAs in Drosophila tissue sections and its application for localizing transcripts of the homeotic Antennapedia gene complex. EMBO I. 2: 617-623.

Hafen, E., A. Kuroiwa, and W.J. Gehring. 1984. Spatial distribution of transcripts from the segmentation gene fushi tarazu during Drosophila embryonic development. Cell 37: 833841.

Hiromi, Y., A. Kuroiwa, and W.J. Gehring. 1985. Control elements of the Drosophila segmentation gene fushi tarazu. Cell 43: 603-613.

Ingham, P.W., K.R. Howard, and D. Ish-Horowicz. 1985. Transcription pattern of the Drosophila segmentation gene hairy. Nature 318: 439-445.

Lawrence, P.A. and G. Morata. 1977. The early development of mesothoracic compartments in Drosophila: An analysis of cell lineage and fate of assessment of method. Dev. Biol. 56: 40-51.

Lehmann, R. and C. Nüsslein-Volhard. 1986. Abdominal segmentation, pole cell formation, and embryonic polarity require the localized activity of oskar, a maternal gene in Drosophila. Cell 47: 141-152. 


\section{Mlodzik et al.}

Lehmann, R. and C. Nüsslein-Volhard. 1987. hunchback, a gene required for segmentation of an anterior and posterior region of the Drosophila embryo. Dev. Biol. 119: 402-417.

Levine, M., K. Harding, C. Wedeen, H. Doyle, T. Hoey, and H. Radomska. 1985. Expression of the homeo box gene family in Drosophila. Cold Spring Harbor Symp. Quant. Biol. 50: 209-222.

Lohs-Schardin, M. 1982. Dicephalic-A Drosophila mutant affecting polarity in follicle organization and embryonic patterning. Wilhelm Roux's Arch. Dev. Biol. 191: 28-36.

MacDonald, P.M. and G. Struhl. 1986. A molecular gradient in early Drosophila embryos and its role in specifying the body pattern. Nature 324: 537-545.

Martinez-Arias, A. and P.A. Lawrence. 1985. Parasegments and compartments in the Drosophila embryo. Nature 313: 639642.

McGinnis, W., M.S. Levine, E. Hafen, A. Kuroiwa, and W.J. Gehring. 1984. A conserved DNA sequence in homeotic genes of the Drosophila Antennnapedia and bithorax complex. Nature 308: $428-433$.

Mitchison, T.J. and J.W. Sedat. 1983. Localization of antigenic determinants in whole Drosophila embryos. Dev. Biol. 99: $261-264$.

Mlodzik, M. and W.J. Gehring. 1987. Expression of the caudal gene in the germ line of Drosophila: Formation of an RNA and protein gradient during early embryogenesis. Cell 48: 465-478.

Mlodzik, M., A. Fjose, and W.J. Gehring. 1985. Isolation of caudal, a Drosophila homeo box-containing gene with maternal expression, whose transcripts form a concentration gradient at the preblastoderm stage. EMBO J. 4: 2961-2969.

Mohler, J. and E.F. Wieschaus. 1986. Dominant maternal-effect mutations of Drosophila melanogaster causing the production of double abdomen embryos. Genetics 112: 803-822.

Nüsslein-Volhard, C. 1977. Genetic analysis of pattern-formation in the embryo of Drosophila melanogaster: Characterization of the maternal-effect mutant bicaudal. Wilhelm Roux's Arch. Dev. Biol. 183: 249-268.

Nüsslein-Volhard, C. 1979. Maternal effect mutations that alter the spatial coordinates of the embryo of Drosophila melanogaster. In Determination of spatial organization (ed. S. Subtelny and I.R. Kornberg), p. 185. Academic Press, New York.

Nüsslein-Volhard, C. and E. Wieschaus. 1980. Mutations affecting segment number and polarity in Drosophila. Nature 287: 795-801.

Rodriguez, J. and F. Deinhardt. 1960. Preparation of a semipermanent mounting medium for fluorescent antibody studies. Virology 12: 316-317.

Schüpbach, T. and E. Wieschaus. 1986a. Germline autonomy of maternal-effect mutations altering the embryonic body pattern of Drosophila. Dev. Biol. 113: 443-448.

. 1986b. Maternal effect mutations altering the anteriorposterior pattern of the Drosophila embryo. Wilhelm Roux's Arch. Dev. Biol. 195: 302-317.

Simon, J.A., C.A. Sutton, R.B. Lobell, R.L. Glaser, and J.T. Lis. 1985. Determinants of heat shock-induced chromosome puffing. Cell 40: 805-817.

Van der Meer, J. 1977. Optical clean and permanent wholemount preparations for phase contrast microscopy of cuticular structures of insect larvae. Dros. Inf. Serv. 52: 160.

Weir, M.P. and T. Kornberg. 1985. Patterns of engrailed and fushi tarazu transcripts reveal novel intermediate stages in Drosophila segmentation. Nature 318: 433-439.

Wieschaus, E. and W.J. Gehring. 1976. Clonal analysis of primordial disc cells in the early embryo of Drosophila melanogaster. Dev. Biol. 50: 249-263. 


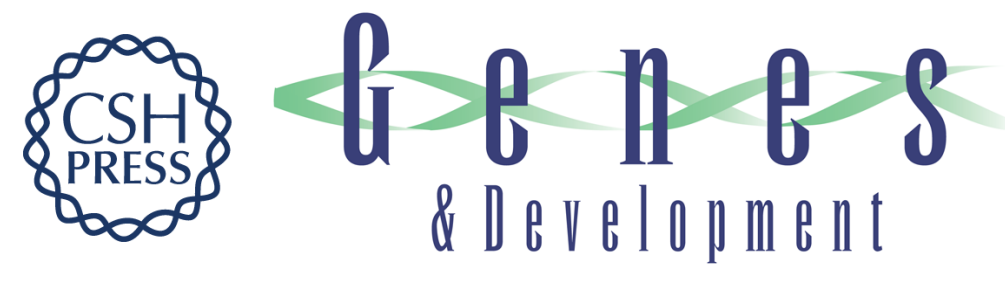

\section{The influence on the blastoderm fate map of maternal-effect genes that affect the antero-posterior pattern in Drosophila}

\section{Genes Dev. 1987, 1:}

Access the most recent version at doi:10.1101/gad.1.6.603

\section{References This article cites 38 articles, 4 of which can be accessed free at: http://genesdev.cshlp.org/content/1/6/603.full.html\#ref-list-1 \\ License}
Email Alerting Service right corner of the article or click here.

